\title{
Quantitation in inflammatory bowel disease using computerised interactive image analysis
}

\author{
EM THOMPSON, ${ }^{*}$ AB PRICE, DG ALTMAN, $†$ C SOWTER, G SLAVIN
}

From the Department of Histopathology, Northwick Park Hospital, Harrow, Middlesex, and the †Department of Computing and Medical Statistics, Clinical Research Centre, Harrow, Middlesex

SUMMARY Objective measurements of various histological features in rectal biopsy material were made using computerised interactive image analysis. Analysis of the resulting data by forward stepwise discriminant analysis showed that biopsies from patients with ulcerative colitis and infective diarrhoea could be distinguished from each other and from normal biopsies; they could not, however, be distinguished from biopsies of patients with Crohn's disease, which behaves as a heterogeneous entity rather than a single disease. The measurements showed that the crypt atrophy described in active ulcerative colitis may be a misnomer, the appearances being due to an increase in mucosal depth and alteration in crypt configuration rather than a true atrophy. Unexpectedly, the ratio of crypt cell height to surface cell height gave the best separation of Crohn's disease from ulcerative colitis.

The differential diagnosis of ulcerative colitis and Crohn's disease continues to be a problem for clinicians, radiologists, and pathologists. Histological distinction is based on subjective assessment of a wide range of criteria, none of which is pathognomonic. The aim of this study was to obtain objective measurements of certain histological criteria using computerised interactive image analysis and to find out which measurements were the most useful in distinguishing ulcerative colitis, Crohn's disease, and other forms of inflammatory bowel disease.

\section{Material and methods}

Rectal biopsy material from the hospital pathology files was selected by working retrospectively from 1980 , choosing only well orientated biopsies. The following categories of inflammatory bowel disease were investigated: ulcerative colitis, Crohn's disease, infective colitis, and a small group without a confident diagnosis. The histological criteria of Morson and Dawson ${ }^{1}$ were used to categorise the biopsies, and histologically normal rectal biopsies were used as controls. All examples of Crohn's disease had granulomata.

Initially, 75 biopsies were studied (series A), and

Present addresses: * Royal Postgraduate Medical School, Du Cane Road, London W12.

¥St Bartholomew’s Hospital, West Smithfield, London EC1.

Accepted for publication 14 February 1985 these comprised 20 normal biopsies, 20 from patients with ulcerative colitis, 20 from patients with Crohn's disease, and 15 from patients with culture positive diarrhoea. The patients with ulcerative colitis included examples with active disease (15) and those with disease in remission (5). Subsequently, another 24 rectal biopsies were studied (series B) in order to assess the validity of the solution provided by stepwise discriminant analysis of the series $A$ biopsies. Thus series B comprised six normal biopsies, six from patients with ulcerative colitis, seven from patients with Crohn's disease, and five from patients with diarrhoea due to Clostridium difficile infection. These were chosen by one author (ABP) and analysed without knowledge of the diagnosis by another (EMT).

As an initial test of clinical usefulness a group of five biopsies on which no firm diagnosis had been made was also analysed and a later clinical follow up examination was made.

Routine $4 \mu \mathrm{m}$ paraffin embedded sections stained with haematoxylin and eosin were satisfactory for most measurements, but for quantitation of epithelial mucin the alcian blue/periodic acid Schiff stain was used.

\section{IMAGE ANALYSIS}

All biopsies were measured using the Magiscan 1 (Joyce-Loebl) image analysis system. A standard 625 line monochrome TV camera scans the microscope image, and the resulting data are fed into a 
$\square$ Epithelial area $\square$ Mucosal area $\square$ Mucin area

$\mathrm{CEH}=$ Crypt epithelial cell height

SEH = Surface epithelial cell height

$M D=$ Mucosal depth $C D=$ Crypt depth

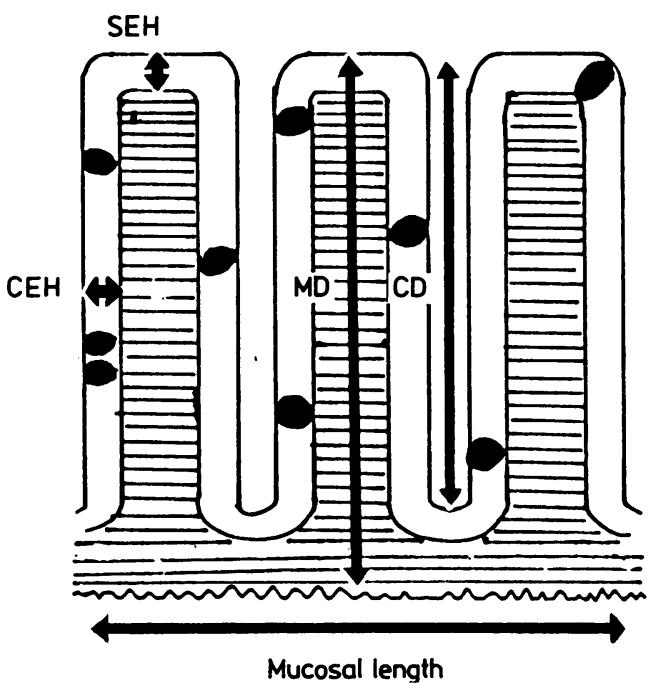

Fig. 1 Line drawing showing the variables which were measured.

special processor which divides the picture into small squares. Each square is given a value, depending on its grey level, between 0 (black) and 63 (white). The boundaries delineating the outer edge of the area of the biopsy to be measured and its associated epithelial boundary are hand drawn using an "electronic pen." The coordinates obtained from these outlines are used to calculate the areas of the epithelium and the stroma and thus total mucosal area. The measurements for crypt depth and cell height were obtained using the same manual technique. For the goblet cell population filters were used to obtain maximum contrast between the mucin cells and their background so that detection could be automatic using grey level thresholding. A manual editing facility was included so that any incorrectly detected cells could be amended.

The following variables were measured (Fig. 1): 1 Epithelial area/mucosal area $(\mathrm{E} / \mathrm{M}) ; 2$ Epithelial area/mucosal length (E/L); 3 Mucin area/mucosal area (MUC/M); 4 Mucin area/mucosal length (MUC/L); 5 Crypt depth (CD); 6 Mucosal depth (MD); 7 Surface epithelial cell height (SEH); 8 Crypt epithelial cell height $(\mathrm{CEH})$-this was the mean of the crypt cell heights taken over the middle two thirds of the crypt. Mucosal length was measured along the muscularis mucosae.

Variables 1 and 2 were intended to measure atrophy, 3 and 4 to measure mucin depletion, and 5 and 6 to assess crypt shortening and mucosal thinning. The ratios $\mathrm{CD} / \mathrm{MD}$ and $\mathrm{SEH} / \mathrm{CEH}$ were also calculated. Two or three fields at $\times 6.3$ magnification according to the size and orientation of the biopsy were measured for each of the first six variables; for SEH and CEH eight fields on the $\times 40$ objective were studied.

\section{Degree of inflammation}

No Magiscan program existed for assessing the degree or quality of inflammation within a biopsy. As these are important in the differential diagnosis of inflammatory bowel disease a subsequent subjective assessment was made on all the biopsies. This was done by agreement using a double headed microscope by two observers (EMT and ABP). Some attempt was made to eliminate bias by having the biopsies coded by a member of the laboratory staff.

The following variables were scored: overall severity of inflammatory cell infiltrate and its overall distribution; the numbers of polymorphonuclear leucocytes; the distribution of polymorphonuclear leucocytes; the numbers of plasma cells.

Assessment was a simple $0,+,++,+++$ system. Variability in distribution was scored as follows: $1=$ focal, $2=$ patchy, $3=$ diffuse (Fig. 2 ).
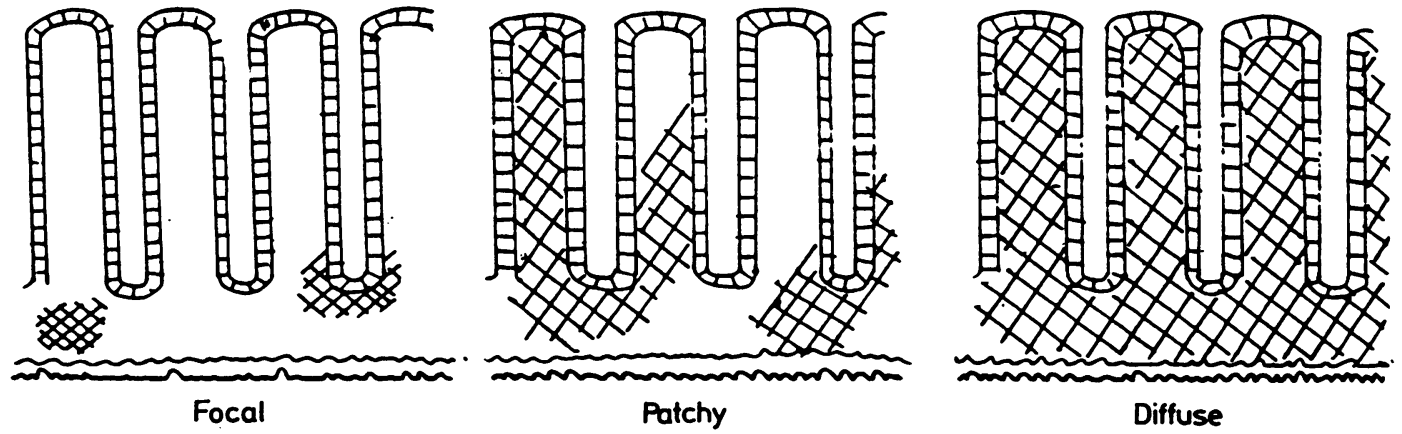

Fig. 2 Line drawing illustrating the different distribution patterns of inflammation (after Yardley and Donowitz'). 

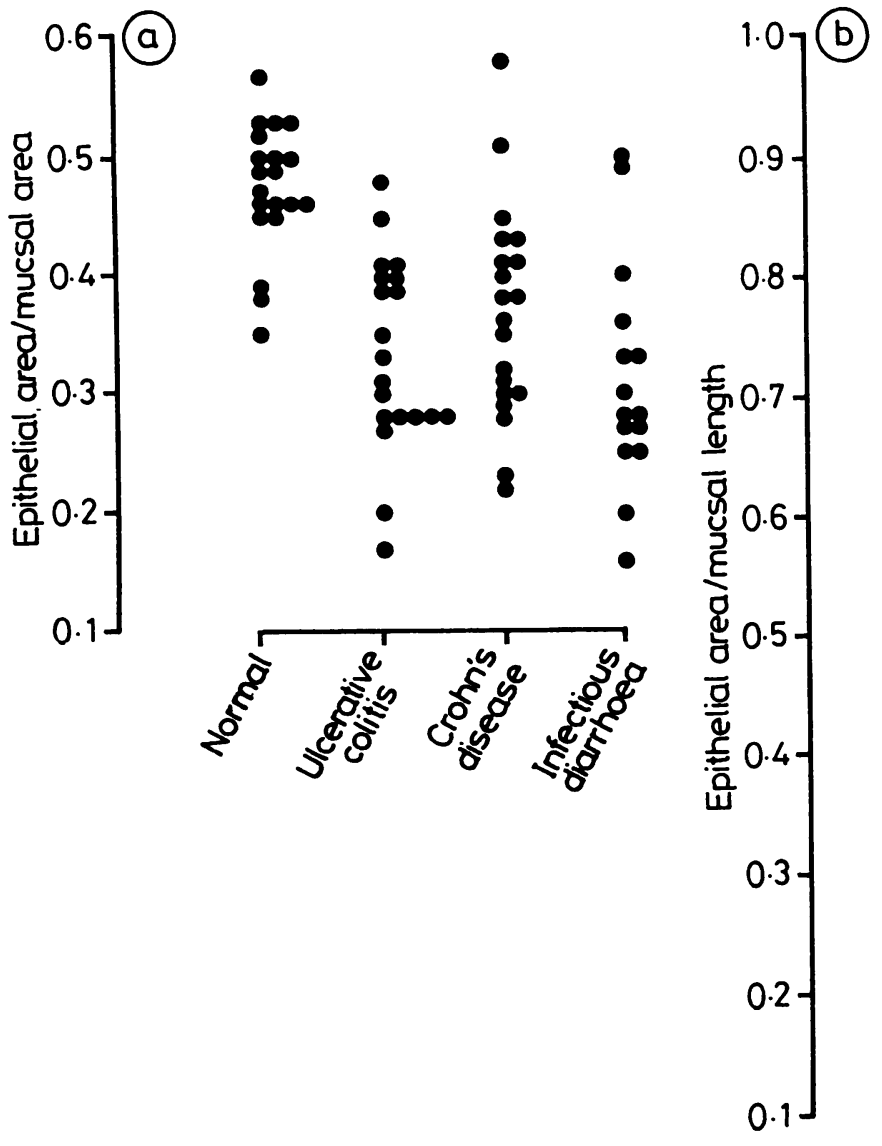

Fig. 3 Epithelial areas expressed (a) as a ratio of total mucosal area and (b) per mucosal length in the four different groups.

STATISTICAL METHODS

The data from series A were analysed using forward stepwise discriminant analysis. ${ }^{2}$ This method is used to try to find the linear-that is, additivecombination of the variables that shows the best separation of the individuals in the different groups. Inherent in this procedure is the identification of those variables which contribute significantly to the discrimination. The criterion for inclusion of a variable was an F value of $\mathbf{3 . 0}$ or more, roughly corresponding to $p=0 \cdot 04$. Further independent combinations of the same variables were also calculated. A plot of the values of the first two linear combination discriminant functions for each individual showed nearly all the separation achieved between the groups. Since the discriminating power would be optimistic when assessed on the same data that were used to derive the discriminant functions, the results for series $A$ incorporated the use of the jack-knife approach. ${ }^{3}$

Both crypt depth and mucosal depth were logarithmically transformed before analysis to remove skewness. The variables relating to the degree of inflammation were all recoded into just two groups: $0,+$, and ++ were combined into one group versus +++ . This was to give reasonable proportions of cases with the poor grade (except in the normal controls). 

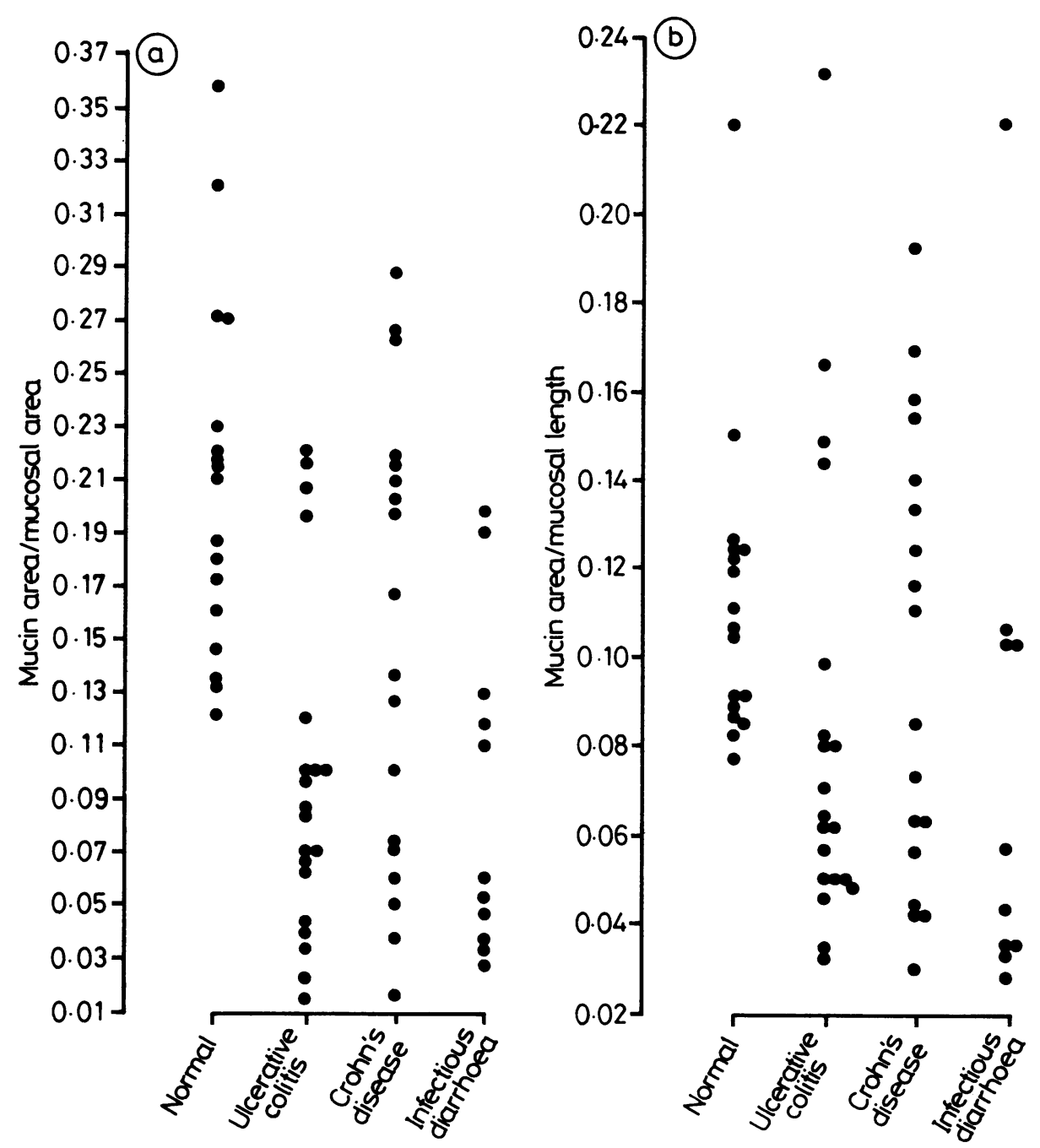

Fig. 4 Mucin area expressed as (a) a ratio of mucosal area and (b) per mucosal length in the four different groups.

\section{Results}

INDIVIDUAL MAGISCAN MEASUREMENTS

Figs. 3-6 show the Magiscan data for the 75 series A biopsies.

STATISTICAL ANALYSIS

The solution produced by discriminant analysis of the Magiscan data alone used four variables. These are shown below in order of importance, with $p$ values relating to removal from the model: 1 Surface epithelial cell height/crypt epithelial cell height (SEH/CEH) (p < 0.00001); 2 Mucosal depth (MD) $(p=0.001) ; 3$ Epithelial area/mucosal area (E/M) $(p=0.003) ; 4$ Crypt depth (CD) $(p=0.003)$.

Of these variables SEH/CEH was easily the most important (Fig. 6c).

When the subjective data on inflammation were included the following variables contributed significantly to the discrimination between groups: 1 SEH/CEH $(p<0.00001) ; 2$ Overall distribution of inflammation ( $p<0.0001) ; 3$ MD $(p=0.002) ; 4$ $E / M(p=0.003) ; 5 C D(p=0.004)$.

Again, the most important variable was SEH/ $\mathrm{CEH}$, followed by overall distribution of inflammation. None of the other variables apart from these five was close to inclusion. Fig. 7 shows a plot of the first two discriminant functions for the model includ- 


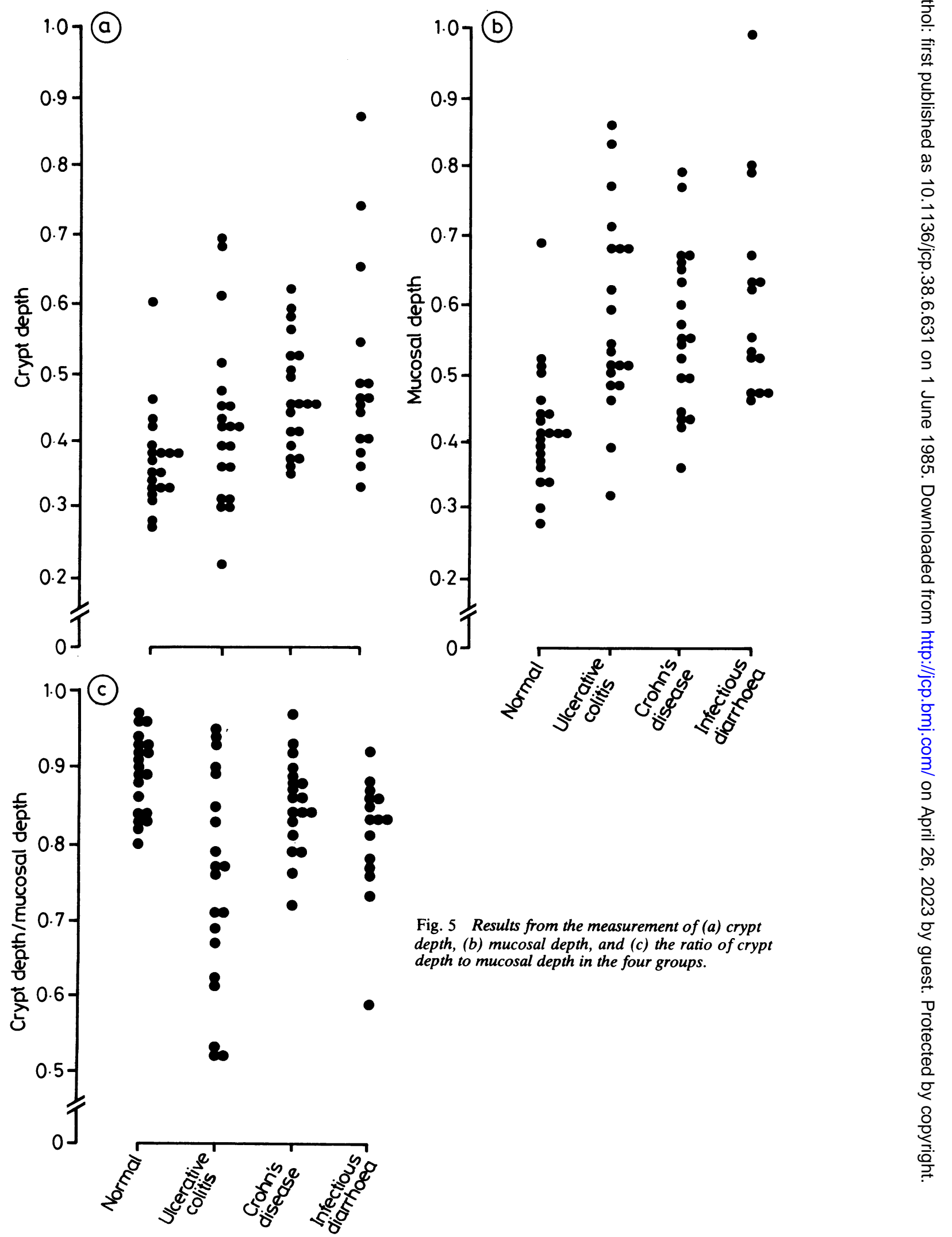



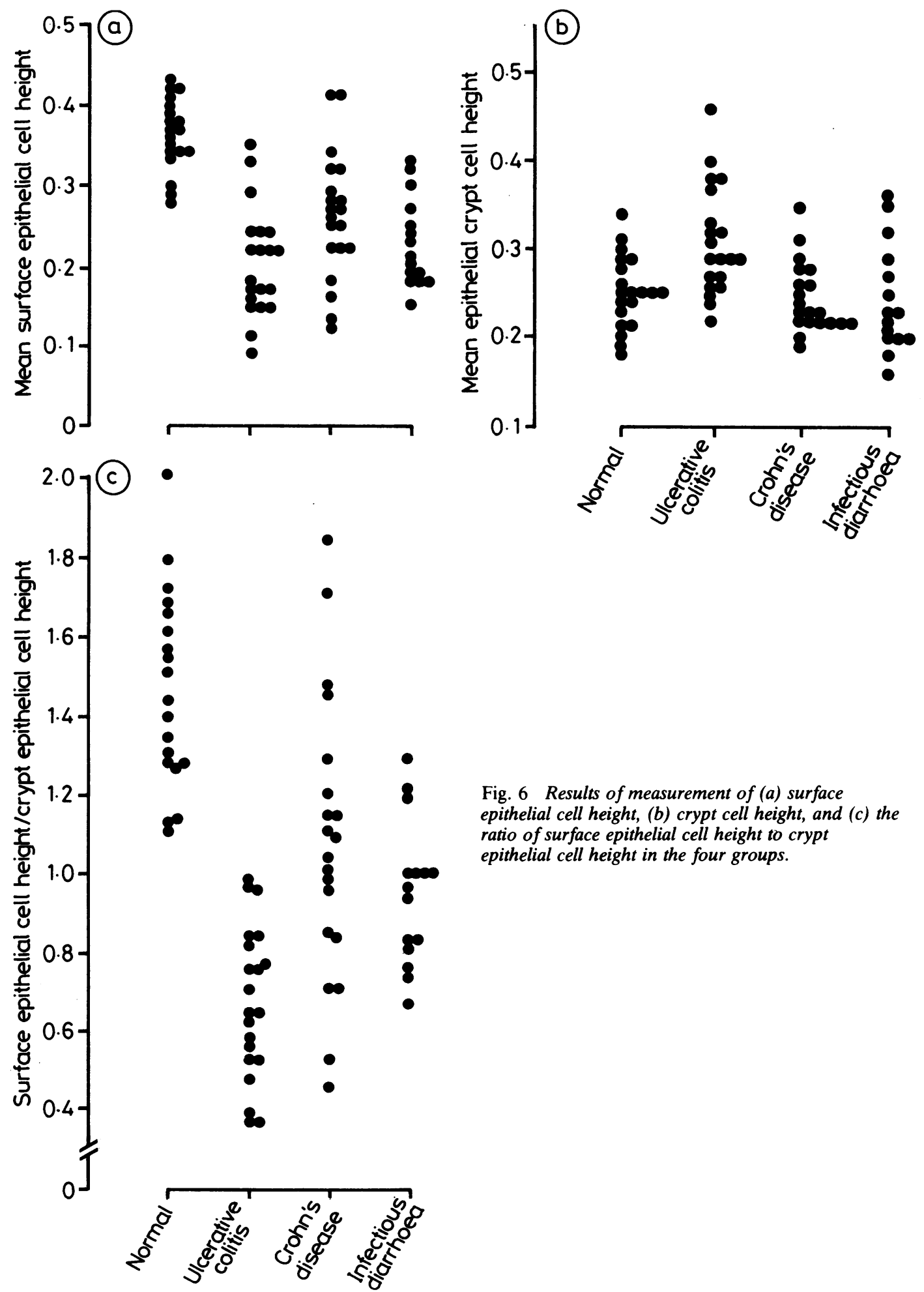

Fig. 6 Results of measurement of (a) surface epithelial cell height, (b) crypt cell height, and (c) the ratio of surface epithelial cell height to crypt epithelial cell height in the four groups. 


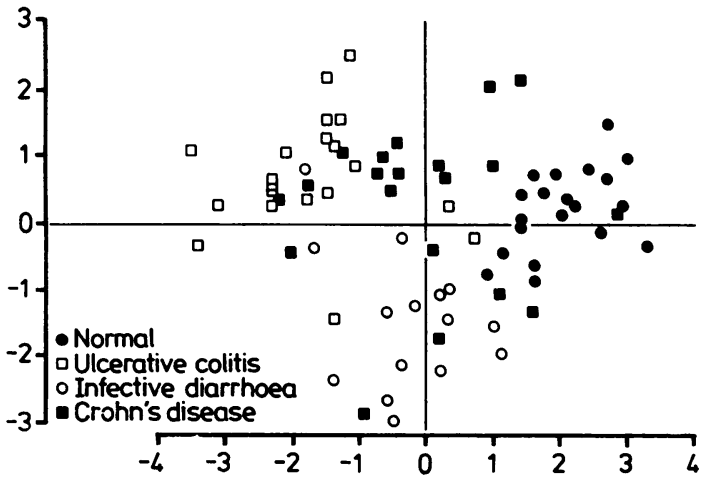

Fig. 7 Graphical representation of the results of stepwise discriminant analysis when the data for inflammation were included.

ing overall distribution. Fig. 8 shows the results of discriminant analysis on the second series of biopsies used to test the system. Tables 1 and 2 show the number of biopsies correctly classified for series A and $\mathrm{B}$. The second model was a clear improvement for series $\mathbf{A}$, but there was no appreciable difference for series B. Table 3 shows how the series A biopsies were misclassified.

Clinical follow up on the five cases without a firm diagnosis three to four years after biopsy showed two biopsies to be probable ulcerative colitis, two to be probable Crohn's disease, and one to be schistosomiasis. The first four were well placed on the plot, but the last was planted firmly in the ulcerative colitis area (see Fig. 8-values of the first and second discriminant functions for the schistosomiasis biopsy were -1.62 and +2.00$)$.

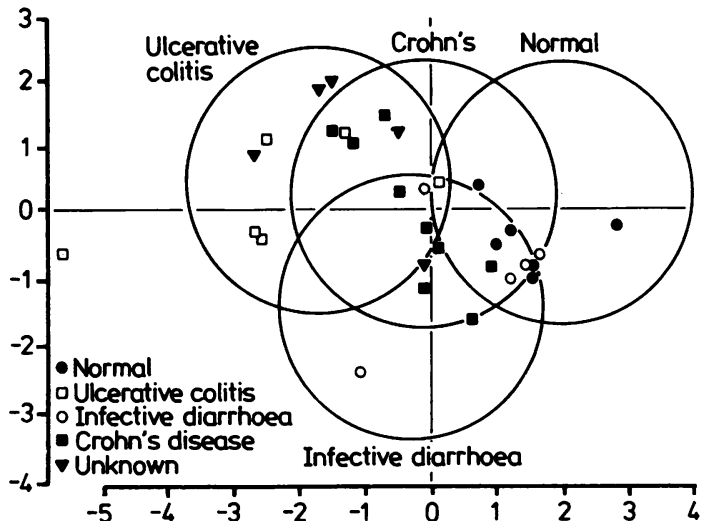

Fig. 8 Graphical representation of the results obtained on the second series of biopsies. Circles, into which about $85 \%$ of patients would be expected to fall, were drawn about the means for each of the different groups.

\section{Discussion}

Figs. 3-6 show that no one variable or selected group of variables could reliably distinguish the different types of inflammatory bowel disease; surprisingly, the ratio of surface epithelial cell height to crypt epithelial cell height (SEH/CEH) was the most successful (Fig. 6c). Part of the explanation for this could be that ulcerative colitis is primarily a mucosal disease and one might expect degeneration of the surface epithelium to be a more consistent finding than it is in Crohn's disease. Furthermore, we have found that crypt goblet cells in resolving ulcerative colitis occasionally appear larger than normal. As this is the first study of the ratio in the published

Table 1 Percentages of series A biopsies which were correctly classified by the computer (incorporating jack-knife)

\begin{tabular}{lllrr}
\hline $\begin{array}{l}\text { Inflammation } \\
\text { included }\end{array}$ & Normal & $\begin{array}{l}\text { Crohn's } \\
\text { disease }\end{array}$ & $\begin{array}{l}\text { Ulcerative } \\
\text { colitis }\end{array}$ & $\begin{array}{l}\text { Infective } \\
\text { diarrhoea }\end{array}$ \\
\hline $\begin{array}{lllr}\text { No } \\
\text { Yes }\end{array}$ & $17 / 20(85 \%)$ & $8 / 20(40 \%)$ & $16 / 20(80 \%)$ & $4 / 15(27 \%)$ \\
\hline
\end{tabular}

Table 2 Percentages of series B biopsies correctly classified in each of the four groups

\begin{tabular}{|c|c|c|c|c|c|}
\hline $\begin{array}{l}\text { Inflammation } \\
\text { included }\end{array}$ & Normal & $\begin{array}{l}\text { Crohn's } \\
\text { disease }\end{array}$ & $\begin{array}{l}\text { Ulcerative } \\
\text { colitis }\end{array}$ & $\begin{array}{l}\text { Infective } \\
\text { diarrhoea }\end{array}$ & Total \\
\hline $\begin{array}{l}\text { No } \\
\text { Yes }\end{array}$ & $\begin{array}{l}3 / 6(50 \%) \\
6 / 6(100 \%)\end{array}$ & $\begin{array}{l}1 / 5(20 \%) \\
1 / 5(20 \%)\end{array}$ & $\begin{array}{l}4 / 7(57 \%) \\
4 / 7(57 \%)\end{array}$ & $\begin{array}{l}5 / 6(83 \%) \\
5 / 6(83 \%)\end{array}$ & $\begin{array}{l}13 / 24(54 \%) \\
14 / 24(58 \%)\end{array}$ \\
\hline
\end{tabular}

Table 3 How the biopsies in each of the four groups were misclassified

\begin{tabular}{|c|c|c|c|c|c|}
\hline & $\begin{array}{l}\text { Percent } \\
\text { correct }\end{array}$ & Normal & $\begin{array}{l}\text { Crohn's } \\
\text { disease }\end{array}$ & $\begin{array}{l}\text { Ulcerative } \\
\text { colitis }\end{array}$ & $\begin{array}{l}\text { Infective } \\
\text { diarrhoea }\end{array}$ \\
\hline $\begin{array}{l}\text { Normal } \\
\text { Crohn's disease } \\
\text { Ulcerative colitis } \\
\text { Infective diarrhoea }\end{array}$ & $\begin{array}{l}95 \% \\
45 \% \\
70 \% \\
80 \%\end{array}$ & $\begin{array}{r}19 \\
3 \\
2 \\
0\end{array}$ & $\begin{array}{l}0 \\
9 \\
2 \\
1\end{array}$ & $\begin{array}{r}0 \\
4 \\
14 \\
2\end{array}$ & $\begin{array}{r}1 \\
4 \\
2 \\
12\end{array}$ \\
\hline
\end{tabular}


work the results need to be substantiated by others before it is established as useful in discrimination of patterns in inflammatory bowel disease. Possible equivalent alterations in cell size are described as a feature of transitional mucosa, a crypt pattern present in many colonic disorders. ${ }^{4}$

It was also surprising to find that measurements such as mucin depletion and crypt length (Figs. 4 and 5a) were poor discriminators of types of inflammatory bowel disease because they are an important part of the armament in subjective analysis. Fig. 5a shows that it is mucosal thickness that increases and crypt depth that alters little. Thus any crypt shortening is more apparent than real and may be explained by two factors. Firstly, in inflamed biopsies mucosal oedema increases the thickness. Secondly, in chronic ulcerative colitis distortion of the crypts may give a false impression of a reduction in crypt length. Although patients with active colitis (15) and those in remission (5) are tabulated together, only one of the biopsies from the group with ulcerative colitis had a crypt depth less than the lower limit of the normal range (Fig. 5a). Clearly, larger numbers need to be examined, especially from cases of ulcerative colitis showing atrophy.

The measurements of epithelial atrophy and mucin depletion were expressed per unit area as well as per unit length of muscularis mucosae. The latter is more suitable as the former expression will not distinguish true atrophy from oedema. In practice, however, the sets of results showed little difference (Figs. 3 and 4).

Although the data on the pattern of inflammation were subjective, they were included because of their importance in distinguishing different types of inflammatory bowel disease. Indeed, their inclusion produced a small improvement in predictive ability, which was most striking in the infective cases for series $\mathbf{A}$ (Tables 1 and 2 ). This is an expected finding from histological studies in the published work. ${ }^{15}$ In series B this improvement was masked, the most likely explanation being the choice of cases with Clostridium difficule infection with classic pseudomembranous colitis rather than salmonella, campylobacter, or shigella infection as in series $\mathrm{A}$. For any given variable the range of values is greatest for patients with Crohn's disease.

Even after stepwise discriminant analysis (Figs. 7 and 8) the patients with Crohn's disease are widely spread, reinforcing the view expressed by others that Crohn's disease constitutes a heterogeneous group ${ }^{6}$ suggesting a multifactorial aetiology. Stepwise discriminant analysis, however, succeeds reasonably well in distinguishing normal rectal mucosa, ulcerative colitis, and infective diarrhoea from each other and highlights a certain homogeneity of the patterns in these two disorders. (Figs. 7 and 8).

This study was both an exploratory and preliminary one. Evaluation on only 24 new biopsies in the second series is far from ideal and in further studies it would probably be better to divide cases of ulcerative colitis into active and atrophic groups. Nevertheless, some interesting results have been obtained, not the least being that while many pathologists feel unhappy when asked to distinguish ulcerative colitis from infective diarrhoea, this study has shown that a realistic separation is possible based on current histological criteria.

\section{References}

'Morson BC, Dawson IMP. Gastrointestinal pathology. 2nd ed. Oxford: Blackwell Scientific Publications, 1979:547-61.

${ }^{2}$ Spicer CC, Hywel Jones J, Lennard-Jones JE. Discriminant and Bayes analysis in the differential diagnosis of Crohn's disease and proctocolitis. Methods Inform Med 1973;12:118-22.

${ }^{3}$ Dixon WJ, ed. BMDP statistical software 1981. Berkeley: University of California, 1981.

${ }^{4}$ Isascson P, Attwood PRA. Failure to demonstrate specificity of the morphological and histochemical changes in mucosa adjacent to colonic carcinoma (transitional mucosa) J Clin Pathol 1979;32:214-8.

${ }^{5}$ Price AB, Jewkes J, Sanderson PJ. Acute diarrhoea, campylobacter colitis and the role of rectal biopsy. J Clin Pathol 1979;32:990-7.

- Hywel Jones J, Lennard-Jones JE, Morson BC, et al. Numerical taxonomy and discriminant analysis applied to non-specific colitis. $Q$ J Med 1973;42:715-32.

' Yardley JH, Donowitz M. Colorectal biopsy in inflammatory bowel disease. In: Yardley JH, Morson BC, Abell MR, eds Gastrointestinal tract. IAP Monograph. Baltimore: Williams and Wilkins Co, 1977:59.

Requests for reprints to: Dr EM Thompson, Department of Histopathology, Royal Postgraduate Medical School, Du Cane Road, London W12 0HS, England. 